\title{
DO ORGANISATIONAL CHARACTERISTICS EXPLAIN THE DIFFERENCES BETWEEN DRIVERS OF ICT ADOPTION IN RURAL AND URBAN GENERAL PRACTICES IN AUSTRALIA?
}

\author{
Robert C. MacGregor \\ School of Information Technology and Computer Science \\ University of Wollongong, Australia \\ rmacgreg@uow.edu.au \\ Peter N. Hyland \\ School of Information Technology and Computer Science \\ University of Wollongong, Australia \\ phyland@uow.edu.au \\ Charles Harvie \\ School of Economics and Information Systems \\ University of Wollongong, Australia \\ charvie@uow.edu.au
}

\begin{abstract}
A number of studies have compared general medical practices in rural locations with those in urban locations. Some of these studies have concentrated on the reasons why a GP might choose to work in a rural or urban setting. Others have examined the type of work required to be undertaken by medical professionals. Increasing use of information and communications technology (ICT) in medical practices has led to some studies examining their use in rural as well as urban settings. However, little if any research has examined whether ICT adoption drivers differ between rural and urban GPs based on their organisational characteristics. This paper presents a study of 198 GPs (122 rural, 76 urban) in Australia. The results show that organisational characteristics are associated with the importance of the drivers for ICT adoption and that these characteristics differ between rural and urban GPs. These findings have important practical and theoretical contributions because it shows that ICT adoption decisions must be contextualised and that it is unlikely that universal adoption drivers will apply to all general practices.
\end{abstract}

Keywords Medical practices, Urban, Rural, Small and Medium Enterprises, SME, Information and Communications Technology, ICT, Adoption 


\section{INTRODUCTION}

Recent years have seen an extraordinary increase in the adoption and use of information and communications technology (ICT), both in large and, more particularly, small businesses. Galloway et al. (2004) suggest that this increase has resulted in, amongst other things, the realisation that context (rural vs. urban) has a direct bearing on the benefits derived from ICT use, the disadvantages incurred through ICT adoption and use and, indeed, the reasons behind decisions being made to adopt ICT, again, particularly in small businesses. It has long been known that ruralbased small-medium enterprises (SMEs) are slower to adopt and use ICT (Leatherman, 2000; Smallbone et al., 2002), a number of studies (Huggins \& Izushi, 2002) point to differences in infrastructure cost and availability between rural and urban-based small businesses contributing to this. More recently, Galliano and Roux (2008) and Black (2005) have shown that differences in competitiveness and access to resources have resulted in differences of 'intensity' with which technology is used.

One particular sector of the small business community that has attracted rural-urban comparisons is the general medical practice sector. Some of these studies (Woloschuk \& Tarrant, 2004; Ciechanowski et al., 2004; Dunt et al., 2006; Farmer et al., 2005; Tolhurst \& Stewart, 2005) have concentrated on the reasons why a GP might choose to work in a rural or urban setting. Others (Tolhurst et al., 2004; Veitch \& Crossland, 2005; Pascoe et al., 2005) have examined the type of work required to be undertaken by medical professionals, while some (Allan \& Schaefer, 2005; Wilkinson et al., 2003; Sargeant, 2005) have concentrated on the ongoing educational requirements for both urban and rural GPs. Recent studies have noted differences both in the treatment methods applied as well as the day-to-day activities within the practices. Simunovic et al. (2007) found less prescriptions being written in rural practices. Hider et al. (2007), in a study of New Zealand GPs made a similar finding, noting also that rural GPs ordered less laboratory tools and had fewer follow-ups with their patients. In a study of Australian GPs, Harris et al. (2007) found rural GPs were more satisfied, worked more closely with colleagues and charged lower fees than their urban counterparts.

While IT has made considerable inroads into general practice, a number of studies (Tjora \& Scrambler, 2009; Robinson et al., 2009; Cho et al., 2008) suggest that many practices, particularly those in rural areas, lag behind other industries. Indeed, studies in the US (Goldschmidt, 2005; Lorence, 2008; Whitten et al., 2008), Australia (Clark et al., 2007) and India (Ganapathy, 2005) show that even when faced with accreditation and funding penalties, many rural practices have made minimal use of technology or, in some cases, retained paper-based systems. A number of these studies (Goldschmidt, 2005; Cho et al., 2008; Clark et al., 2007) suggest that a 'one size fits all' approach to adoption and use by government and medical agencies fails to take into account the organisational characteristics surrounding the use of the technology. Examples of organisational characteristics include the size of the practice in terms of number of GPs and number of patients, as well as employee skills with medical packages, word processing, etc. They suggest that while ICT systems may suit larger urban medical practices, they do not always suit the day-to-day work of smaller and/or rural practices. While overall differences in adoption and use have been shown in the literature, what remains unclear is the role of organisational characteristics on the ICT adoption decision-making process and whether these differ between rural and urban medical practices.

The purpose of this study is to examine why GPs adopt ICT in Australia (termed the drivers of adoption) and, in particular, whether organisational characteristics affect the rating of importance of drivers for ICT adoption and whether these differ between urban and rural GPs. This paper has important theoretical contributions because if ICT adoption drivers are rated differently by urban and rural GPs (especially in terms of their organisational characteristics), then it would suggest that 
researchers should not look for universal adoption factors. Instead, it would imply that ICT adoption theories should contextualise the drivers in terms of the location of businesses, their individual characteristics, and so on. We also argue in this paper that understanding the ways in which organisational characteristics affect decision-making by GPs could help policy makers develop more effective programs that expedite ICT adoption.

The paper begins by briefly examining the differences in urban and rural medical practices. The paper then examines the use of ICT in medical practices. As the study will examine the drivers for ICT adoption and the role of organisational characteristics in that process, the paper provides a detailed evaluation of the literature concerned with drivers for ICT adoption and organisational characteristics. Finally, the paper then presents a study of 198 GPs (122 rural, 76 urban) in Australia. A series of linear regressions is applied to the data to determine if there are differences in the effect of organisational characteristics on ICT adoption drivers between urban and rural GPs. Results are discussed and conclusions are drawn.

\section{LITERATURE REVIEW}

\section{Urban and Rural General Practice}

It is important to outline the key differences between urban and rural GPs generally in order to understand the impact of their organisational characteristics on ICT adoption, and to appreciate why their adoption decisions might vary.

More than $60 \%$ of Australian GPs work in urban areas, most working in group practices located in community-based offices. GPs in urban areas often create their own niche within the complex network of potential service and patients, and tend to be more consumerist than those in rural locations (Allan \& Schaeffer, 2005; Deans \& MacDonald, 2006; Lepnurm et al., 2007). Compared to rural practitioners, urban GPs have a range of specialists which they can call upon and refer their patients to rather than undertake the treatment themselves. Urban GPs will visit patients in hospital and nursing homes but rarely undertake home visits.

Rural GPs tend, by contrast, to be 'Jacks of all trades' (that is, undertaking many specialist roles themselves because specialist services are not locally available) and are often regarded as community leaders (MacLellan, 2006 cited in Lepnurm et al., 2007). Harris et al. (2007) found that rural GPs saw a greater number of patients, made decisions without consultation with specialists (such as coronary care, stroke or geriatric physicians), and were more satisfied with their career than urban GPs. While more were satisfied with their career, rural GPs were less satisfied with government decision-making concerning rural medical practice (Swan et al., 2008). Unlike the consumerist approach of urban patients, rural patients usually form a relationship with their GP (Harris et al 2007). Rural GPs also tend to perform more diagnostic and preventative procedures but less corrective procedures than urban GPs, and they are far more restricted by practice size, practice population spread and the location of secondary care (Lepnurm et al., 2007).

It is therefore clear that there are many differences between urban and rural GPs and that these differences are due (in part) to organisational characteristics such as the number of patients and GPs. The next section explores the use of ICT by GPs and the limited research comparing urban and rural GPs in terms of their ICT use. This leads to the conclusion that further research is needed to examine whether organisational characteristics help explain the differences in ICT adoption decisions by urban and rural GPs. 


\section{The Use of ICT in General Practice}

The use of ICT within medical practices is by no means a new phenomenon. An examination of the literature provides numerous studies describing both the design of clinical ICT systems (PelletierFleury et al., 1999; Baldwin et al., 2002; Hsu et al., 2005) as well as the uses of such systems within the practice or healthcare facility (Ammenwerth et al., 2003; Waring \& Wainwright, 2002; Shohet \& Lavy, 2004; Catalan, 2004). Not only is the technology being used for clinical purposes, it now incorporates the wider role of business and practice management (Lougheed, 2004; Stevanovic et al., 2005; Keddie \& Jones, 2005; Ho et al., 2004; Ash et al., 2004). At first glance these may appear to be at odds with one another, with clinical use aimed at quality and efficiency of medical care, and with business use aimed at profitability and budgetary concerns. However, recent studies (Bonneville \& Pare, 2006; Lievens \& Jordanova, 2004; Rahimi \& Vimarlund, 2007) suggest that, for any medical or healthcare function to be truly viable, there must be a balance between medical and business efficiency. Indeed, Kuruvilla et al. (2004) suggest that the use of ICTs in general practice not only centralises geographically dispersed resources, thus promoting flexibility and economies of scale, but also promotes efficiency, enhances quality of care and encourages partnerships both between practitioners as well as between patients and practitioners.

Despite the seemingly widespread use of ICT in general practices, a number of studies suggest that for reasons of location, practice size or finance, the level of use still remains less than uniform. In a recent US study, Lee et al. (2005) found that only $11.3 \%$ of medical practices in smaller communities were fully utilising ICT capabilities, compared with substantially higher rates in urban locations. They suggested that the main reason for the lower use of ICT in smaller community medical practices is the lack of funds, time and ICT know-how. Similar studies in Hong Kong (Leung et al., 2003) noted that lack of know-how and fear of computer technology reduced the use of ICTs in general practice. A recent article examining the needs of rural and urban GPs in Australia (Allan \& Schaefer, 2005) found that, in comparison with their urban counterparts, rural GPs had a far lower knowledge of computer technology and its uses in medical care. A number of recent studies (Cho \& Mathiassen, 2007; Eckman et al., 2007; Gold \& Ball, 2007; Mechanic, 2008) have found that differences in work procedures have given rise to difficulties in simply transferring medical systems from urban locations to rural ones.

It is unclear from this limited research whether organisational characteristics might help explain these differences between urban and rural GPs in their ICT adoption and use. More specifically, it raises the question of whether organisational characteristics explain why urban and rural GPs impinge on the drivers governing their ICT adoption. The next section therefore identifies and describes the drivers which the literature suggests might influencing the ICT adoption decisions of GPs, and the following section identifies and describes the key organisational characteristics.

\section{Drivers for ICT Adoption}

There have been many studies that have examined the drivers behind ICT adoption in the general business sector (MacGregor \& Vrazalic, 2007; Chong \& Pervan, 2007). A number of these drivers are applicable to general practices including the potential for ICT to reduce costs (Eid et al., 2006; Raisch, 2001); improve internal efficiency (Anvari, 2007); strengthen relations with business partners (Raymond, 2001; MacGregor \& Vrazalic, 2007); improve control of the business (Overall \& Blobel, 2007; Valcke \& Wever, 2006) and, of course, the pressures applied from outside to adopt and use the technology (Grandon \& Pearson, 2004; Marang-Van de Mheen et al., 2006). Compton et al. (2007) notes that while there are some drivers that come from general business, others are only of importance to medical and healthcare workers. Table 1 therefore summarises the drivers of ICT adoption for general practices based on an analysis of the available literature, and each driver is described in more detail in this section. 


\begin{tabular}{|c|c|c|}
\hline Driver & Description & Literature Support \\
\hline Pressure from patients & $\begin{array}{l}\text { Patients requiring the GP to have ICT } \\
\text { capabilities. In some cases patients have } \\
\text { been included in designing ICT solutions }\end{array}$ & $\begin{array}{l}\text { Agrawal et al. (2007); Cho and Mathiassen (2007); } \\
\text { Klein (2007); Lorence (2008); Whitten et al. (2008) }\end{array}$ \\
\hline $\begin{array}{l}\text { Pressure from medical } \\
\text { suppliers }\end{array}$ & $\begin{array}{l}\text { Suppliers of medical equipment and } \\
\text { materials, demanding that this be done via } \\
\text { ICT }\end{array}$ & $\begin{array}{l}\text { Ash et al. (2004); Grandon and Pearson (2004); Ho et } \\
\text { al. (2004); Keddie and Jones (2005); Lougheed } \\
\text { (2004); Riehle et al. (2008); Stevanovic et al. (2005) }\end{array}$ \\
\hline $\begin{array}{l}\text { Pressure from medical } \\
\text { authorities }\end{array}$ & Pressure from medical authorities & $\begin{array}{l}\text { Deans and MacDonald (2006); Lorence (2008); } \\
\text { Whitten et al. (2008) }\end{array}$ \\
\hline $\begin{array}{l}\text { Pressure from } \\
\text { competing GPs }\end{array}$ & Pressure from competing GPs & $\begin{array}{l}\text { Lougheed (2004); Stevanovic et al. (2005); Keddie } \\
\text { and Jones (2005); Ho et al. (2004); Ash et al. (2004); } \\
\text { Riehle et al. (2008) }\end{array}$ \\
\hline $\begin{array}{l}\text { Improved information } \\
\text { storage and retrieval }\end{array}$ & $\begin{array}{l}\text { Reduction of errors and duplication } \\
\text { through better information storage and } \\
\text { retrieval }\end{array}$ & $\begin{array}{l}\text { Agrawal et al. (2007); Chon et al. (2008); Gagnon et } \\
\text { al. (2009); Goldschmidt (2005); Papazafeiropoulou } \\
\text { and Gandecha (2007); Riehle et al. (2008); Stahl and } \\
\text { Brooke (2008) }\end{array}$ \\
\hline $\begin{array}{l}\text { Improved } \\
\text { communication }\end{array}$ & $\begin{array}{l}\text { Improved communication to labs, } \\
\text { radiology, etc. leading to improved disease } \\
\text { management assistance in admissions, } \\
\text { discharges and billing }\end{array}$ & $\begin{array}{l}\text { Cherry et al. (2002); Christensen and Remler (2007); } \\
\text { Gagnon et al. (2009); Harrison and McDowell } \\
\text { (2008); Husk and Waxman (2004); Robinson et al. } \\
\text { (2009) }\end{array}$ \\
\hline $\begin{array}{l}\text { Reduction of business } \\
\text { costs }\end{array}$ & Reduction of administration costs & $\begin{array}{l}\text { Cho and Mathiassen (2007); Christensen and Remler } \\
\text { (2007); Gagnon et al. (2009); Goldschmidt (2005); } \\
\text { Riehle et al. (2008); Stahl and Brooke (2008) }\end{array}$ \\
\hline $\begin{array}{l}\text { Improved business } \\
\text { efficiency }\end{array}$ & $\begin{array}{l}\text { ICT improves both clinical and business } \\
\text { practices }\end{array}$ & $\begin{array}{l}\text { Cho and Mathiassen (2007); Christensen and Remler } \\
\text { (2007); Gagnon et al. (2009); Goldschmidt (2005); } \\
\text { Riehle et al. (2008); Stahl and Brooke (2008) }\end{array}$ \\
\hline $\begin{array}{l}\text { Improved patient } \\
\text { care/contact }\end{array}$ & $\begin{array}{l}\text { Telemedicine, contact with other medical } \\
\text { colleagues and treatment of chronic } \\
\text { illnesses }\end{array}$ & $\begin{array}{l}\text { Anvari (2007); Christensen and Remler (2007); } \\
\text { Martin et al. (2009); Mohr (2008); Rahimi and } \\
\text { Vimarland (2007); Wan et al. (2007) }\end{array}$ \\
\hline $\begin{array}{l}\text { Improved capacity to } \\
\text { support systematic } \\
\text { approaches to disease } \\
\text { management }\end{array}$ & $\begin{array}{l}\text { Reduction of duplication and improvement } \\
\text { of both clinical and business practices, } \\
\text { leading to better disease management }\end{array}$ & $\begin{array}{l}\text { Agrawal et al. (2007); Andersson et al. (2002); } \\
\text { Baldwin et al. (2002); Gagnon et al. (2009); Harrison } \\
\text { and McDowell (2008); Pelletier-Fleury et al. (1999); } \\
\text { Qavi et al. (2001); Riehle et al. (2008); Robinson et } \\
\text { al. (2009); Stahl and Brooke (2008) }\end{array}$ \\
\hline $\begin{array}{l}\text { Streamline billing and } \\
\text { accounting }\end{array}$ & $\begin{array}{l}\text { Better administration practices and quicker } \\
\text { accounting turnaround }\end{array}$ & $\begin{array}{l}\text { Chon et al. (2008); Goldschmidt (2005); } \\
\text { Papazafeiropoulou and Gandecha (2007) }\end{array}$ \\
\hline $\begin{array}{l}\text { Strengthen relations } \\
\text { with business partners }\end{array}$ & $\begin{array}{l}\text { Ability for business partnerships to make } \\
\text { quicker and more reliable decisions }\end{array}$ & Eckman et al. (2007) \\
\hline Facilitate e-commerce & Purchases/billing, etc & $\begin{array}{l}\text { Gagnon et al. (2009); Riehle et al. (2008); Stahl and } \\
\text { Brooke (2008) }\end{array}$ \\
\hline $\begin{array}{l}\text { Keep in touch with } \\
\text { medical and other } \\
\text { developments }\end{array}$ & $\begin{array}{l}\text { Ability to consult databases and have } \\
\text { access to medical and government } \\
\text { authorities }\end{array}$ & $\begin{array}{l}\text { Agrawal et al. (2007); Gagnon et al. (2009); Lucas } \\
\text { (2008) }\end{array}$ \\
\hline Generate prescriptions & Generate prescriptions & $\begin{array}{l}\text { Chon et al. (2008); Papazafeiropoulou and Gandecha } \\
\text { (2007); Robinson et al. (2009) }\end{array}$ \\
\hline $\begin{array}{l}\text { Keep in contact with } \\
\text { hospitals }\end{array}$ & Keeping in contact with hospitals & $\begin{array}{l}\text { Harrison and McDowell (2008); Husk and Waxman } \\
\text { (2004); Robinson et al. (2009) }\end{array}$ \\
\hline
\end{tabular}

Table 1: Drivers for ICT Adoption in General Practices

A number of recent studies (Klein, 2007; Lorence, 2008; Agrawal et al., 2007; Cho \& Mathiassen, 2007; Whitten et al., 2008) have begun to examine the approaches used to design medical and healthcare systems. These studies note that there is a move towards recognising and incorporating the needs of all stakeholders in the design effort. Thus, where in the past many of these systems were designed with the clinician in mind, there is now a conscious effort to include patient views. While much of this is 'push-driven with minimal pull from potential adopters' (Cho \& Mathiassen, 2007, p738), the studies do suggest that there is a desire by patients for GPs to have ICT-based systems for diagnosis, treatment and ongoing management of disease. This introduces the driver pressure from patients. 
Research undertaken by Grandon and Pearson (2004), Raymond (2001) and Mehrtens et al. (2001) has shown that many general small businesses have been forced to use Internet-based systems by their larger business partners. This is no less the case with the medical and healthcare sector. Several studies (Lougheed, 2004; Stevanovic et al., 2005; Keddie \& Jones, 2005; Ho et al., 2004; Ash et al., 2004; Riehle et al., 2008) have shown that general practitioners are now demanding that ICT systems incorporate the wider role of business and practice management. This, it is suggested, is in answer to the pressure from medical suppliers and pressure from medical authorities

As already noted, previous studies (Deans \& MacDonald, 2006; Lorence, 2008; Whitten et al., 2008) suggest that patients, particularly those in urban areas, are becoming more consumerist with their choice of GP. This has meant that there is a level of competitiveness amongst GPs. It has been suggested that the ability of ICT to speed up diagnosis and treatment has been a contributing component of this pressure from competing GPs.

One of the obvious advantages of ICT, in general and for small businesses as well as the health and medical sector, is the improved information storage and retrieval. Studies in the US (Chon et al., 2008) have shown that over 90,000 deaths annually can be attributed to medical errors. Studies in Europe and the US (Agrawal et al., 2007; Papazafeiropoulou \& Gandecha, 2007; Goldschmidt, 2005; Chon et al., 2008) note that errors are substantially reduced with the introduction of ICT. More recently, studies (Riehle et al., 2008; Stahl \& Brooke, 2008; Gagnon et al., 2009) have shown that the introduction of ICT is usually accompanied by improvements to administrative tasks, including the use of data.

One obvious enhancement brought about through the use of ICT is improved communication. Studies by Cherry et al. (2002) and Christensen and Remler (2007) have shown that enhanced communication not only aids the diagnosis and treatment of disease, but actually reduces the costs entailed in these processes. Recent systems (Husk \& Waxman, 2004; Harrison \& McDowell, 2008; Robinson et al., 2009; Gagnon et al., 2009) are now linking the communication functions to clinical verification, enhanced admission and discharge procedures and improved patient billing.

Two areas that all businesses look at from the adoption of technology is a reduction of business costs and improved business efficiency (Kaynak et al., 2005; MacGregor \& Vrazalic, 2007). As already noted, previous studies (Agrawal et al., 2007; Goldschmidt, 2005; Cho \& Mathiassen, 2007; Christensen \& Remler, 2007) have shown that the use of ICT reduces costs of diagnosis and treatment. Similarly, other studies (Riehle et al., 2008; Stahl \& Brooke, 2008; Gagnon et al., 2009) have shown that the use of ICT improves medical and business efficiency within the practice.

Christensen and Remler (2007) have concluded that ICTs are an effective means of continuous treatment for chronic diseases. Today, the use of ICT is being incorporated into an 'arsenal' of medical tools in general practice, in a more systematic way (Anvari, 2007). Uses include: teleconsultation and tele-education (Rahimi \& Vimarlund, 2007; Lucas, 2008); oncology and dermatology (Mohr, 2008); cardiovascular treatment (Wan et al., 2007); psychiatry (Mohr, 2008); computer assisted decision-making (Agrawal et al., 2007); smart home technologies for social-care support (Martin et al., 2009) and neurological care (Ganapathy, 2005). All of these uses of ICT by GPs can help with improved patient care/contact.

A number of studies have suggested that paramount to improving patient care is the improved capacity to support systematic approaches to disease management (Agrawal et al., 2007; Gagnon et al., 2009). Findings suggest that the use of ICT reduces administration time, allowing a greater concentration on the clinical aspects of the practice (Riehle et al., 2008; Stahl \& Brooke, 2008). Other benefits leading to a more systematic approach to disease management include contact with other clinicians regarding patient care (Qavi et al., 2001; Baldwin et al., 2002); elimination of redundancy in patient care (Pelletier-Fleury et al., 1999); enhancements to the effectiveness of the 
practice (Andersson et al., 2002) and improvement to laboratory information systems (Harrison \& McDowell, 2008; Robinson et al., 2009).

Other medical drivers for ICT adoption that have been examined in the literature include the ability to keep in touch with medical and other developments (Agrawal et al., 2007; Gagnon et al., 2009; Lucas, 2008); the ability to generate prescriptions and includes checking drug interactions (Papazafeiropoulou \& Gandecha, 2007; Robinson et al., 2009; Chon et al., 2008) and to keep in contact with hospitals, nursing homes, etc (Husk \& Waxman, 2004; Harrison \& McDowell, 2008).

As already noted, the use of ICT in medical and healthcare facilities not only enhances patient treatment but assists the practice in normal business activities. The literature has shown the following to be potential drivers for ICT adoption and use: the ability to streamline billing and accounting functions (Papazafeiropoulou \& Gandecha, 2007; Chon et al., 2008; Goldschmidt, 2005); to facilitate e-commerce (Gagnon et al., 2009; Riehle et al., 2008; Stahl \& Brooke, 2008); and to strengthen relations with business partners, particularly where a practice is owned by many GPs (Eckman et al., 2007; MacGregor \& Vrazalic, 2007).

As stated previously, the limited existing research in this area means that there is no clear understanding of whether the organisational characteristics of these general practices affect the impact of these ICT adoption drivers when comparing urban and rural GPs. The next section examines the organisational characteristics which might affect the rating of these drivers by urban and rural GPs.

\section{Organisational Characteristics that Affect the Rating of Drivers for ICT Adoption}

Many studies have examined the role of organisational characteristics on ICT adoption in small businesses in general. These include business size (MacGregor \& Vrazalic, 2007); the age of the business (Vrazalic et al., 2002; Daniel et al., 2002); the level of ICT skill within the business (O’Donnell et al., 2001; MacGregor \& Vrazalic, 2007); and the existence/non-existence of an IT professional in the small business (MacGregor, 2008). More recently, a number of researchers have begun to look at some of these same organisational characteristics in the context of ICT adoption in the medical and healthcare sector. Table 2 summarises theses characteristics for general practices in particular.

\begin{tabular}{|l|l|}
\hline \multicolumn{1}{|c|}{ Organisational Characteristic } & \multicolumn{1}{c|}{ Literature Support } \\
\hline Practice size in terms of the number of GPs & $\begin{array}{l}\text { Burt et al. (2007 cited in Reardon \& Davidson } \\
\text { 2007); Lorence (2008); Reardon and Davidson } \\
\text { (2007); Simon et al. (2007) }\end{array}$ \\
\hline Practice size in terms of the number of patients & Reardon and Davidson (2007) \\
\hline ICT skills & $\begin{array}{l}\text { Chon et al. (2008); Reardon and Davidson } \\
\text { (2007); Lorence (2008) }\end{array}$ \\
\hline
\end{tabular}

Table 2: Organisational Characteristics Affecting the Rating of ICT Adoption Drivers

Some studies (such as Simon et al., 2007; Burt et al., 2007 cited in Reardon \& Davidson, 2007) have found that practices with more than seven GPs were four times more likely to adopt ICT technology than those with fewer GPs. Similar studies (Reardon \& Davidson, 2007; Lorence, 2008) found the cost of investing in the technology, fear of productivity loss and lack of any financial incentives were the main reasons behind smaller practices not adopting ICT. These findings suggest that the size of the practice (in terms of number of GPs and patients) could be a relevant organisational characteristic, because larger practices would have fewer financial burdens and require fewer financial incentives when compared to their smaller competitors. 
Not only is there a potential financial burden being placed on the practice because of its size, but early studies (Fichman \& Kemerer, 1997) suggest that larger practices have a greater learningrelated scale suggesting greater diverse knowledge and skills leading to a greater likelihood of assimilating complex organisational technology. In a study of 130 medical practices in the US, Reardon and Davidson (2007) found that practices with a larger number of GPs or with a wider variety of IT skills, were more likely to adopt and use ICT. For this reason, the level of ICT skills was also considered to be a potential organisational characteristic affecting ICT adoption.

\section{RESEARCH METHOD}

The aim of this study is to determine whether organisational characteristics affect the rating of importance of drivers for ICT adoption, and whether these differ between urban and rural GPs. The drivers making up Table 1 and the organisational characteristics making up Table 2 were used as the basis for a series of interviews with urban and rural practitioners that had adopted ICT. The aim of the interviews was to determine whether the list in Tables 1 and 2 were applicable and complete. The interviews showed that the list of drivers was applicable and complete, however the IT skills characteristic was further subdivided into word processing skills, medical packages skills and invoice generation skills. These then formed the basis of a questionnaire.

It should be noted that all GPs in Australia practice within a Division of General Practice, the specific division dependent on the geographic location of the practice. There are many divisions of general practice within Australia, each containing approximately 200 - 300 GPs, each having a head of division and each staffed by GPs and non-medical staff. The role of the division is to disseminate material to GPs, deal with disputes etc. and to keep members in touch with latest developments (medical, legal, finance etc.).

Ten divisions were contacted and asked to participate in the study. Six (Western Sydney, Illawarra, Hunter, Ballarat, South East NSW and Rockhampton) agreed. Questionnaires were sent to each division for distribution to members. Each questionnaire had a replied-paid envelope back to the researchers. As such, details of divisional membership were not disclosed. 890 surveys (500 to rural GPs and 390 to urban GPs) were distributed across the 6 divisions. Respondents were asked, amongst other things, to rate the importance of drivers of ICT adoption across a 5 point Likert scale ( 1 very unimportant, 5 very important). Respondents were also asked to provide details of organisational characteristics (size of the practice in terms of employees, number of patients per week) as well as ratings of the three IT skills. As already indicated, other studies (Reardon \& Davidson, 2007; Lorence, 2008) suggest that IT skills may be a function of practice size. In order to compensate for this possibility, a series of linear regressions were applied to the data.

\section{RESULTS}

Of the 890 surveys distributed, 198 were returned and meant a response rate of $20.2 \%$. Of these responses 122 (24.4\%) were from rural GPs and 76 (19.5\%) were from urban GPs. Table 3 provides a profile of respondents. 


\begin{tabular}{|l|l|l|}
\cline { 2 - 3 } \multicolumn{1}{c|}{} & Urban & Rural \\
\hline Staff numbers & & \\
\hline $1-2$ & $11(14 \%)$ & $30(24 \%)$ \\
\hline $3-5$ & $26(34 \%)$ & $55(45 \%)$ \\
\hline $6-10$ & $18(24 \%)$ & $22(18 \%)$ \\
\hline $11-20$ & $10(13 \%)$ & $12(10 \%)$ \\
\hline$>20$ & $2(3 \%)$ & $2(1 \%)$ \\
\hline Invalid & $2(3 \%)$ & $1(0.5 \%)$ \\
\hline Patient numbers/week & & \\
\hline$<30$ & $6(8 \%)$ & $3(2.5 \%)$ \\
\hline $30-60$ & $11(14 \%)$ & $17(14 \%)$ \\
\hline $60-90$ & $10(13 \%)$ & $17(14 \%)$ \\
\hline $90-120$ & $17(22 \%)$ & $30(24 \%)$ \\
\hline $120-150$ & $12(15 \%)$ & $27(22 \%)$ \\
\hline$>150$ & $13(13 \%)$ & $27(22 \%)$ \\
\hline Invalid & $7(9 \%)$ & $1(0.5 \%)$ \\
\hline Dedicated IT person & & \\
\hline Yes & $39(52 \%)$ & $68(56 \%)$ \\
\hline No & $30(39 \%)$ & $53(43 \%)$ \\
\hline Invalid & $7(9 \%)$ & $1(0.5 \%)$ \\
\hline
\end{tabular}

\begin{tabular}{|l|l|l|}
\cline { 2 - 3 } \multicolumn{1}{c|}{} & Urban & Rural \\
\hline Invoice generating skills & & \\
\hline Very poor & $17(22 \%)$ & $30(25 \%)$ \\
\hline Poor & $21(29 \%)$ & $29(24 \%)$ \\
\hline Average & $10(13 \%)$ & $17(14 \%)$ \\
\hline Good & $10(13 \%)$ & $30(25 \%)$ \\
\hline Very good & $6(8 \%)$ & $11(9 \%)$ \\
\hline Invalid & $12(15 \%)$ & $5(4 \%)$ \\
\hline Medical package skills & & \\
\hline Very poor & $3(4 \%)$ & $3(2.5 \%)$ \\
\hline Poor & $3(4 \%)$ & $8(6 \%)$ \\
\hline Average & $15(20 \%)$ & $22(18 \%)$ \\
\hline Good & $23(30 \%)$ & $58(38 \%)$ \\
\hline Very good & $23(30 \%)$ & $27(22 \%)$ \\
\hline Invalid & $9(12 \%)$ & $4(3 \%)$ \\
\hline Word processing skills & & \\
\hline Very poor & $2(3 \%)$ & $4(3 \%)$ \\
\hline Poor & $4(6 \%)$ & $18(15 \%)$ \\
\hline Average & $26(34 \%)$ & $36(30 \%)$ \\
\hline Good & $27(35 \%)$ & $42(34 \%)$ \\
\hline Very good & $8(10 \%)$ & $18(15 \%)$ \\
\hline Invalid & $9(12 \%)$ & $4(3 \%)$ \\
\hline
\end{tabular}

Table 3: Profile of Respondents

Before applying any statistical examination it was imperative to determine whether sufficient sample size had been achieved. The following formula for sample size was used, as suggested by Skane (1985) and MacGregor (2008):

$$
\text { or } \quad \begin{aligned}
& \mathbf{E}=\mathbf{z}_{\boldsymbol{\alpha} / 2} \boldsymbol{\sigma} / \sqrt{ } \mathbf{n} \\
& \mathbf{n}=\left(\mathbf{z}_{\alpha / 2} \boldsymbol{\sigma} / \mathbf{E}\right)^{2}
\end{aligned}
$$

At $99.9 \%$ degree of confidence $\mathbf{z}_{\boldsymbol{\alpha} / \mathbf{2}}$ was determined to be 2.59 .

The highest value for $\boldsymbol{\sigma}$ was 2.71

The margin of error was 1 .

The minimum sample size needed based on this formula was 50 (rounded up), which meant that there were sufficient responses for statistical analysis. A series of Levene tests were carried out to determine homogeneity of variance. The Levene's tests provided a significance of $<.001$ for all questions being examined, indicating that data was sufficiently robust to apply linear regressions.

Table 3 shows that rural practices tend to have fewer staff and saw more patients per week when compared to urban practices, which is consistent with the literature (see Harris et al., 2007). However, it should be noted that number of staff and the number of patients per week were not statistically significant when comparing urban and rural practices. It is also evident from Table 3 that there were no differences between rural and urban practices in terms of having a dedicated IT person. An examination of the rating of particular skills, again, shows that there were no significant 
differences between the rural and urban GP respondents. This was confirmed when no statistical significance was found when comparing the the ICT skills of the rural and urban GP respondents.

The aim of the study was to determine whether organisational characteristics affect the ratings of importance of drivers for ICT adoption and to determine whether these differ between rural and urban GPs. A series of linear regressions was applied to the drivers and the results are shown in Table 4. It should be noted that only the significant results are displayed. For the current study the direction of Beta is of importance, not so much its value. A positive Beta means that as one value increases across the Likert scale, so does the other.

\begin{tabular}{|c|c|c|c|c|c|}
\hline \multirow{2}{*}{ Driver } & \multirow[b]{2}{*}{ Organisational characteristics } & \multicolumn{2}{|c|}{ URBAN } & \multicolumn{2}{|c|}{ RURAL } \\
\hline & & Beta & Signif. & Beta & Signif. \\
\hline Pressure from patients & No significance with any characteristics & & & & \\
\hline Pressure from medical suppliers & No significance with any characteristics & & & & \\
\hline Pressure from medical authorities & No significance with any characteristics & & & & \\
\hline Pressure from competing GPs & No significance with any characteristics & & & & \\
\hline \multirow{4}{*}{$\begin{array}{l}\text { Improved information storage and } \\
\text { retrieval }\end{array}$} & Level of skill - medical packages & .370 & .000 & .349 & .006 \\
\hline & Level of skill - Word processing & .294 & .024 & \multicolumn{2}{|c|}{ No significance } \\
\hline & ICT Administrator & -.189 & .017 & \multicolumn{2}{|c|}{ No significance } \\
\hline & Size of practice (no. of employees) & .191 & .036 & \multicolumn{2}{|c|}{ No significance } \\
\hline \multirow[t]{4}{*}{ Improved communication } & Level of skill - medical packages & .322 & .002 & .342 & .009 \\
\hline & Size of practice (no. of employees) & \multicolumn{2}{|c|}{ No significance } & .246 & .042 \\
\hline & Level of skill - Word processing & .342 & .009 & \multicolumn{2}{|c|}{ No significance } \\
\hline & ICT Administrator & -.196 & .013 & \multicolumn{2}{|c|}{ No significance } \\
\hline \multirow[t]{2}{*}{ Reduction of business costs } & Level of skill - medical packages & .236 & .046 & .466 & .001 \\
\hline & Size of practice (patients/week) & .293 & .001 & \multicolumn{2}{|c|}{ No significance } \\
\hline Improved business efficiency & Level of skill - medical packages & .256 & .023 & .458 & .001 \\
\hline \multirow{3}{*}{ Improved patient care/contact } & Level of skill - medical packages & \multicolumn{2}{|c|}{ No significance } & .471 & .001 \\
\hline & ICT Administrator & -.240 & .006 & \multicolumn{2}{|c|}{ No significance } \\
\hline & Size of practice (no. of employees) & .190 & .036 & \multicolumn{2}{|c|}{ No significance } \\
\hline \multirow{3}{*}{$\begin{array}{l}\text { Improved capacity to support a } \\
\text { systematic approach to disease } \\
\text { management }\end{array}$} & Level of skill - medical packages & .238 & .031 & .402 & .005 \\
\hline & ICT Administrator & -.258 & .004 & \multicolumn{2}{|c|}{ No significance } \\
\hline & Size of practice (no. of employees) & .219 & .015 & \multicolumn{2}{|c|}{ No significance } \\
\hline $\begin{array}{l}\text { Streamline billing and accounting } \\
\text { functions }\end{array}$ & Level of skill - medical packages & .338 & .003 & .415 & .003 \\
\hline \multirow{2}{*}{$\begin{array}{l}\text { Strengthen relations with business } \\
\text { partners }\end{array}$} & Size of practice (no. of employees) & .200 & .019 & \multicolumn{2}{|c|}{ No significance } \\
\hline & Size of practice (patients/week) & .311 & .000 & \multicolumn{2}{|c|}{ No significance } \\
\hline \multirow[t]{3}{*}{ Facilitate e-Commerce } & Level of skill - Generating invoices & \multicolumn{2}{|c|}{ No significance } & .321 & .024 \\
\hline & Level of skill - medical packages & \multicolumn{2}{|c|}{ No significance } & .292 & .036 \\
\hline & ICT Administrator & \multicolumn{2}{|c|}{ No significance } & .258 & .020 \\
\hline $\begin{array}{l}\text { Keep in touch with medical and } \\
\text { other developments }\end{array}$ & Level of skill - Generating invoices & \multicolumn{2}{|c|}{ No significance } & .310 & .034 \\
\hline Generating prescriptions & Level of skill - medical packages & .546 & .000 & .512 & .000 \\
\hline & Size of practice (no. of employees) & .309 & .000 & No sig & ificance \\
\hline Keep in contact with hospitals & Size of practice (no. of employees) & .183 & .040 & No sig & ificance \\
\hline & Size of practice (patients/week) & .252 & .006 & No sig & ificance \\
\hline
\end{tabular}

Table 4: Summary of Linear Regressions

The first observation from Table 4 is that four drivers (pressure from patients, pressure from suppliers, pressure from medical authorities and pressure from competing GPs) are not associated with any of the organisational characteristics of either rural or urban respondents. The result was an expected outcome of the study. While a number of studies (Lee et al., 2005; Allan \& Schaefer, 2005; Leung et al., 2003) have shown that a bi-product of the urban-rural divide has been increased 
pressure on rural GPs to 'catch up' to their urban counterparts, this is not the case for urban GPs. One obvious reason for this is the fact that the technical infrastructure and economic basis for Australian GPs is far more uniform between urban and rural areas, and this might explain why there are no differences noted for external pressure from patients, suppliers and competitors.

Table 4 suggests, however, that there are seven ICT adoption drivers for which the organisational characteristics appear to indicate a number of differences between urban and rural GPs: improved information storage and retrieval; improved communication; improved patient care/contact; improved capacity to support a systematic approach to disease management; strengthen relations with business partners; facilitate e-Commerce; and keep in contact with hospitals. With these drivers various organisational characteristics differed between urban and rural practices in terms of their statistical significance. More specifically:

- $\quad$ For the driver improved information storage and retrieval, it can be seen that both rural and urban respondents showed a significant association between this driver and the organisational characteristic level of skill with medical packages. In both cases, those GPs who perceived their skill to be higher also rated this driver as being more important. However, the results also show that three other organisational characteristics of urban respondents were significantly associated with this driver but were not significant for rural respondents: level of perceived skill in word processing, the existence/non-existence of an ICT administrator and the size of the practice (number of employees). The results suggest that urban GPs who have a higher perceived level of skill in word processing and/or have an ICT administrator and/or work in larger practices placed a higher level of importance on the driver improved information storage and retrieval. While the question of prior IT experience was not asked, this result appears to suggest that practices with longer prior experience with IT see the benefits of improving information storage and retrieval. The results also appear to suggest that prior IT experience may be more the norm with larger urban practices and far less the norm in rural practices. Another possible reason is that rural GPs tend to form closer relationships with their patients (Harris et al 2007) and therefore do not need to use ICT to record and retrieve information about their patients, or they prefer non-ICT methods of recording patient information.

- For the driver improved communication there was a significant association with the organisational characteristics level of skill with medical packages for both rural and urban respondents, just as it was for the previous driver improved information storage and retrieval. However, the results also show that three other organisational characteristics differed between urban and rural respondents. Rural respondents also showed an association with the size of the practice (number of employees) which suggests that rural GPs who worked in larger practices rated this driver as being more important than those from smaller practices. It is surprising that this was not also the case for urban GPs as it was for the previous driver, with one possible explanation being that there was far more consensus amongst urban GPs about the importance of ICT for improved communication irrespective of their size. For urban respondents, two organisational characteristics perceived level of skill with word processing and existence/nonexistence of an ICT administrator were significantly associated with the driver improved communication. In other words, those urban GPs who were in a practice that had an ICT administrator and/or perceived their skill with word processing as being higher gave higher ratings to the driver. This would be expected because those with greater ICT capability would be expected to perceive improved communication as a benefit. This might not be the case for rural GPs because they do not require ICT for communication purposes.

- For the driver improved patient care/contact the rural and urban respondents differed on three organisational characteristics. Rural respondents who perceived their level of skill with medical packages as being higher rated this driver as being more important. This would be expected 
because medical packages might be designed to help GPs manage patients. Urban respondents, by contrast, whose practices had an ICT administrator and/or came from larger size of practice (number of employees) rated the driver more highly. While the existence of an IT administrator may be more common in urban practices, the question still arises as to why there are no associations with the level of IT skills for urban respondents.

- For the driver improved capacity to support a systematic approach to disease management when both rural and urban respondents rated their level of skill with medical packages as high, they also rated this driver as more important. However, two other organisational characteristics existence/non-existence of an ICT administrator and size of the practice (number of employees) were significantly associated with this driver in the case of urban respondents but not for rural respondents. In other words, those urban respondents whose practice had an ICT administrator and/or came from larger practices were more likely to rate this driver as being more important than urban practices without an ICT administrator or which were smaller. This is perhaps not surprising when considering that using ICT to improve disease management would require higher level ICT skills and would be more important in larger practices where there is many staff who need to keep track of patients. But it is surprising that this does not hold for rural practices (as was also the case with the driver improved information storage and retrieval). One possible reason for this might be that larger rural practices maintain more interpersonal relationships between the GP and patient, so that ICT is not as critical for disease management.

- $\quad$ For the driver strengthen relations with business partners two organisational characteristics were significantly associated with this driver for urban respondents but not for rural respondents: size of the practice in terms of both employees and number of patients per week. In other words, GPs from larger practices (either in terms of staff or patients) were more likely to rate this driver as being more important. One possible explanation for this is that larger urban practices might be more likely to have business partners, so that strengthening these relations is an important issue. The literature suggests that rural practices, by contrast, tend to be 'Jacks of all trades' (MacLellan, 2006 cited in Lepnurm et al., 2007) and therefore might rely less on business partners, thus accounting for the lack of association for rural respondents.

- $\quad$ For the driver facilitate e-Commerce there were three organisational characteristics of rural respondents which were significantly associated with this driver, but not for urban respondents: perceived level of skill with generating invoices; the perceived level of skill with medical packages; and the existence/non-existence of an ICT administrator. The results show that rural GPs who have a higher perceived level of skill either in generating invoices or using medical packages rated this driver higher than those with a lower level of skill. The results also show that those who do not have an ICT administrator rated the driver more highly. This suggests that rural practices with more sophisticated ICT capability are more likely to recognise the importance of using ICT to facilitate e-Commerce. While this is perhaps not surprising, it is interesting that this did not seem to apply to urban respondents. This might reflect that rural practices (with ICT capability) are more likely to order supplies online given their isolation, while urban practices do not necessarily rely on e-Commerce for ordering because of their close proximity to predominantly urban suppliers.

- For the driver keep in contact with hospitals the two organisational characteristics relating to practice size (in terms of employees and number of patients per week) were associated with this driver by urban respondents but not for rural respondents. Those urban GPs which worked in larger practices rated this driver as more important than those from smaller practices. This is perhaps not surprising because larger urban practices, with more patients, would be more likely to have frequent contact with hospitals than smaller urban practices and therefore require ICT to support this communication. What was more surprising, however, was the lack of significant 
associations regarding rural respondents, even for larger rural practices. This might reflect that rural GPs use other means of keeping in contact with hospitals. This might also be due to rural GPs and patients using regional hospitals where ICT-based contact is not necessary.

For the remaining ICT drivers the organisational characteristics appeared to be much less helpful in explaining the differences driver ratings by urban and rural GPs. Only one organisational characteristic was different for each of four drivers (reduction of business costs, keep in touch with medical and other developments and generating prescriptions) and for two drivers (improved business efficiency and streamline billing and accounting functions) there were no differences between urban and rural practices on the basis of organisational characteristics. More specifically:

- For the driver keep in touch with medical and other developments rural respondents who perceived their level of skill at generating invoices as being higher rated this driver as being more important, while rural GPs without this skill rate the driver as unimportant. The underlying reasons behind this association are not clear and require further analysis. One possible explanation is that skills with ICT in generating invoices are similar to the skills which are needed by rural GPs to use ICT to keep up with medical and other developments. The lack of any association with organisational characteristics for urban GPs suggests that there is little perceived difference between urban GPs as to their views concerning the need to keep in touch with medical and other developments.

- For the driver generating prescriptions both rural and urban respondents showed a significant association between the perceived level of skill using medical packages and this driver, as would be expected if the medical packages help generate prescriptions. The results also show that for urban respondents who worked in a large size of practice (number of employees) were more likely to rate this driver as being more important. Again this association is expected because those working for large practices would see prompt generation of invoices as vital. However, it is a little surprising that large rural practices do not see this as important.

- For the driver reduction of business costs both rural and urban respondents with higher perceived level of skill with medical packages rated this driver higher (as expected), while only urban respondents with a larger size of practice (number of patients per week) also rated this driver higher. While it is expected that larger practices would need to be more concerned about how to reduce costs, it is a little surprising that this only appears to be the case for urban practices and not rural practices.

It is perhaps not surprising that rural and urban respondents who perceived their level of skill with medical packages to be high also rated the drivers improved business efficiency and streamline billing and accounting higher. However, it is surprising that size of practice in terms of patients seen per week was not also associated with these two drivers, because as the number of patients increase it would be expected that efficiency, billing and accounting would depend on ICT.

\section{DISCUSSION}

Facilitating the adoption and use of ICT in general medical practices must be seen as a key to the improvement of patient care and practice administration. As already detailed, the use of ICT can provide quicker error-free information to diagnose, treat and manage patient care. Vital to the ongoing development of ICT-based systems is their applicability and usefulness to both rural and urban doctors. Understanding what organisational characteristics affect decision-making may help policy makers develop more effective programs that expedite ICT adoption. 
In summarising the findings, it can be seen from Table 4 that for rural GPs the apparent overriding organisational characteristic associated with the majority of the ICT adoption drivers is the perceived level of skill with medical packages. For 11 of the 16 drivers examined, the level of perceived importance of the driver increased with the level of skill with medical packages. However, the results do not confirm direction of this association. In other words, the findings do not confirm whether medical package skill results in higher ratings of the drivers, or whether recognition by rural respondents of the drivers encourages them to develop skills with medical packages. Nonetheless, if it is the former then the results would suggest that government policy makers, medical authorities and vendor organisations should consider ways in which these skills can be enhanced to reduce barriers to potential adoption of ICT. A number of programs centred on learning laboratories, community resources, user groups and vendor-based training have already been developed in the US (Reardon \& Davidson, 2007) and these may be adaptable to the Australian condition. This suggests the need for further research to investigate the impact of ICT skills development on ICT adoption in rural practices.

For urban GPs the two overriding organisational characteristics which appear to affect decisionmaking concerning ICT adoption are skills with medical packages and the size of the practice itself (either in terms of number of staff or patients seen each week). While urban and rural respondents were almost identical in their rating of the drivers in terms of skill with medical packages, they differed considerably when it came to size of practice. More specifically, it was only large urban practices which rated many of the drivers higher, while the size of rural practice had no association with the drivers (except improved communication). This might confirm the studies (Olatunde et al., 2007; Harris et al., 2007; Deans \& McDonald, 2006) showing that urban practices are far more consumerist than rural practices. For example, the findings suggest that as urban practices grow they require ICT to keep track of patients, perhaps because patients are seen by different GPs on each visit and ICT is needed for continuity of care and/or because relationships between a GP and a patient are not the focus of such practices. For rural practices, however, even large rural practices do not necessarily adopt ICT for patient management purposes, perhaps because they focus on interpersonal relationships between a GP and a patient regardless of practice size. If a rural patient always sees the same GP, then ICT might not be as critical for managing patients. This suggests that further research is needed to examine the ways in which large urban and rural practices manage their patients, how they maintain relationships (if at all), and the role of ICT in these contexts.

The results concerning the impact of medical package skills and size of practice for urban practices are similar to those found in several US studies (Reardon \& Davidson, 2007; Lorence, 2008). What perhaps is most interesting is that these US studies found that mandating the adoption and use of ICT systems often led to minimal use or, in some cases, complete abandonment of the system. This suggests that further research is needed to determine whether similar ICT adoption mandates are occurring in Australia and whether there is a backlash by GPs in smaller urban practices which might account for the lower rating of drivers by these urban respondents.

One question that was not asked in the current study, but should be addressed, is whether providing financial incentives to overcome investment costs might promote ICT use. Studies (Reardon \& Davidson, 2007; Lorence, 2008) suggest that both rural and small urban practices respond very differently to ICT adoption when a financial encouragement is included.

These findings therefore provide some important insights which need to be taken into account with future research aiming to build theory relating to ICT adoption by SMEs, and general practices in particular. This paper has shown that, as argued by Parker and Castleman (2007; 2009), it is unwise to conduct research which looks for universal adoption factors which apply to all SMEs. Instead, the adoption of ICT (and the associated drivers) must be contextualised to take into account the specific circumstances of each business such as their location, industry, business goals, ICT skill levels, and 
so on. For example, the findings seem to suggest that rural GPs (regardless of their size) might be more concerned about maintaining interpersonal relationships with their patients, and might perceive ICT as being irrelevant (or even contrary) to this business goal. Similarly, this research has shown that there appear to be considerable differences among GPs when rating adoption drivers in terms of their location (rural versus urban), practice size and ICT skill level. For this reason, a failure by researchers to understand this complex mix of contextual factors will result in ICT adoption theories which do not adequately explain the ICT adoption decisions of SMEs.

\section{LIMITATIONS OF THE STUDY}

It should be noted that this study has some limitations. The data for the study was collected from several areas in Australia. Therefore, although conclusions can be drawn, the results may not be generalisable to other countries. Also, this is a quantitative study, and further qualitative research is required to gain a better understanding of the key issues.

\section{CONCLUSION}

The purpose of this study has been to determine if organisational characteristics affect the rating of importance of drivers for ICT adoption and to determine if these differ between urban and rural GPs. The results show that several organisational characteristics of GPs are associated with the importance of the drivers for ICT adoption, and that these characteristics differ between rural and urban GPs.

The results derived from the study are important for medical authorities, government bodies dealing with ICT adoption, practices themselves as well as researchers into ICT adoption in general practice. While many studies have been concerned with the benefits derivable from ICT adoption and use, a number (Lee et al., 2005; Leung et al., 2003; Allen \& Schaeffer, 2005) have noted that rural practices and some smaller urban practices are less inclined to adopt ICT. In the past there has been an underlying assumption that this is because of cost, lack of time or lack of technical knowledge. This study has shown that there are a number of characteristics of the general practices which also need to be considered when examining rural practices. For both the medical and government authorities these additional characteristics are crucial, particularly where they are involved in promoting ICT in rural areas. An examination of the literature put out by medical and government authorities appears to be underpinned with the view that general practices are for the most part uniform. The results presented here would tend to negate these views and emphasise the importance of understanding the contextual factors of the practices in order to understand their decisions regarding whether to adopt ICT.

As already indicated, this study is part of a larger examination of ICT adoption and use in the Australian medical sector. Further results examining benefits and disadvantages will be forthcoming. 


\section{REFERENCES}

Agrawal, R., Grandison, T., Johnson, C. \& Kiernan, J. (2007) "Enabling the 21st Century Healthcare Information revolution", Communications of the ACM, Vol 50 No 2, pp 34-42.

Allan, J.A. \& Schaefer, D. (2005) "Do the learning needs of rural and urban general practitioners differ?", Australian Journal of Rural Health, Vol 13, pp 337-342.

Ammenwerth, E., Mansmann, U., Iller, C. \& Eichstadter, R. (2003) "Factors Affecting and Affected by User Acceptance of Computer-Based Nursing Documentation: Results of a Two-year Study", Journal of the American Medical Informatics Association, Vol 10 No 1, pp 69-84.

Andersson, A., Vimarlund, V. \& Timpka, T. (2002) "Management Demands on Information and Communication Technology in Process-Oriented Health-care Organisations", Journal of Management in Medicine, Vol 16 No 2/3, pp 159-169.

Anvari, M. (2007) "Impact of information technology on human resources in healthcare", Healthcare Quarterly, Vol 10 No 4, pp 84-88.

Ash, S., Gorman, P.N., Seshadri, V. \& Hersh, W.R. (2004) "Perspectives on CPOE and Patient Care", Journal of the American Medical Informatics Association, Vol 11 No 2, pp 95-99.

Baldwin, L.P., Clarke, M. \& Jones, R. (2002) "Clinical ICT Systems: Augmenting Case Management", Journal of Management in Medicine, Vol 16 No 2/3, pp 188-198.

Black, G.S. (2005) "Is eBay for Everyone? An Assessment of Consumer Demographics", S.A.M. Advanced Marketing Journal, Vol 70 No 1, pp 50-59.

Bonneville, L. \& Pare, D.J. (2006) "Socioeconomic Stakes in the Development of Telemedicine", Journal of Telemedicine and Telecare, Vol 12 No 5, pp 217-219.

Catalan, J. (2004) "Internet Medicine Sales and the Need for Homogeneous Regulation International", Journal of Medical Marketing, Vol 4 No 4, pp 342-349.

Cherry, J.C., Moffatt, T.P., Rodriguez, C. \& Dryden, K. (2002) "Diabetes Disease Management Program for an Indigent Population Empowered by Telemedicine Technology", Diabetes Technology and Therapeutics, Vol 11 No 6, pp 783-791.

Cho, S., Mathiassen, L. \& Nilsson, A. (2008) "Contextual Dynamics During Health Information Systems Implementation : An Event-Based Actor-Network Approach", European Journal of Information Systems, Vol 17 No 6, pp 614-630.

Cho, S. \& Mathiassen, L. (2007) "The Role of Industry Infrastructure in Telehealth Innovations: A Multi-Level Analysis of a Telestroke Program", European Journal of Information Systems, Vol 16 No 6, pp 738-750.

Chon, A., Watson, R.T. \& Boudreau, M.-C. (2008) "Ubiquitous Access: On the Front Lines of patient Care and Safety", Communications of the ACM, Vol 51 No 6, pp 95-99.

Chong, S. \& Pervan, G. (2007) "Factors Influencing the Extent of Deployment of Electronic Commerce for Small-and-Medium-Sized Enterprises” Journal of Electronic Commerce in Organizations, Vol 5 No 1, pp 1-29.

Christensen, M.C. \& Remler, D. (2007) "Information and Communications technology in Chronic Disease Care", Medical Care Research and Review, Vol 64 No 2, pp 123-147. 
Ciechanowski, P.S., Russo, J.E., Katon, W.J. \& Walker, E.A. (2004) "Attachment theory in health care: the influence of relationship style on medical students' specialty choice", Medical Education, Vol 38, pp 262-270.

Clark, R.A., Eckert, K.A., Stewart, S., Phillips, S.M., Yallop, J.J., Tonkin, A.M. \& Krum, H. (2007) "Rural and urban differentials in primary care management of chronic heart failure: new data from the CASE study", Medical Journal of Australia, Vol 186 No 9, pp 441-445.

Compton, S., Lang, E., Richardson, T.M. \& Hess, E. (2007) "Knowledge Translation Consensus Conference: Research Methods”, Academic Emergency Medicine, Vol 14 No 11, pp 991.

Daniel, E.M., Wilson, H. \& Myers, A. (2002) “Adoption of e-commerce by SMEs in the UK: towards a stage model”, International Small Business Journal, Vol 20 No 3, pp 253-270.

Deans, G. \& MacDonald, J. (2006) "Rural/urban differences in accounts of patients' initial decision to consult primary care", Health \& Place, Vol 12 No 2, pp 210-221.

Dunt, D., Elsworth, G., Southern, D., Harris, C., Potiriadis, M. \& Young, D. (2006) "Individual and area factors associated with general practitioner integration in Australia: A multilevel analysis", Social Science and Medicine, Vol 63, pp 680-690.

Eckman, B.A., Bennett, C.A., Kaufman, J.H. \& Tenner, J.W. (2007) "Varieties of Interoperability in the transformation of the health-care information infrastructure", IBM Systems Journal, Vol 46 No 1, pp 19-41.

Eid, R., Trueman, M. \& Ahmed, A.M. (2006) "B2B international internet marketing: A benchmarking exercise”, Benchmarking, Vol 13 No 1/2, pp 200-213.

Farmer, J., Iversen, L., Campbell, N.C., Guest, C., Chesson, R., Deans, G. \& MacDonald, J. (2005) "Rural/urban differences in accounts of patients' initial decisions to consult primary care", Health \& Place, Vol 12, pp 210-221.

Fichman, R.G. \& Kemerer, C.F. (1997) "The Assimilation of Software Process Innovations: An Organizational Learning Perspective", Management Science, Vol 43 No 10, pp 1345-1363.

Gagnon, M.P., Legare, F., Labrecque, M., Fremont, P., Pluye, P., Gagnon, J., Car, J., Pagliari, C., Desmartis, M., Turcot, L. \& Gravel, K. (2009) "Interventions for Promoting Information and Communication technologies Adoption in Healthcare Professionals", The Cochrane Collaboration, Vol 2, pp 1-31.

Galliano, D. \& Roux, P. (2008) "Organisational motives and spatial effects in Internet adoption and intensity use: evidence from French industrial firms", The Annals of Regional Science, Vol 42 No 2, pp 425-448.

Galloway, L., Mochrie, R. \& Deakins, D. (2004) "ICT-enabled collectivity as a positive rural business strategy International", Journal of Entrepreneurial Behaviour \& Research, Vol 10 No 4, pp 247-259.

Ganapathy, K. (2005) "Telemedicine and neurosciences", Journal of Clinical Neuroscience, Vol 12 No 8, pp 851-862.

Gold, J.D. \& Ball, M.J. (2007) "The Health Record banking Imperative: A Conceptual Model", IBM Systems Journal, Vol 46 No 1, pp 43-55.

Goldschmidt, P.G. (2005) "HIT and MIS: Implications of Health Information Technology and Medical Information Systems", Communications of the ACM, Vol 48 No 10, pp 69-74. 
Grandon, E. \& Pearson, J.M (2004) "E-commerce Adoption: Perception of Managers/Owners of Small and Medium Sized Firms in Chile”, Communications of the Association of Information Systems, Vol 13, pp 81-102.

Harris, M.F., Proudfoot, J.G., Jayasinghe, U.W., Holton, C.H., Powell-Davies, G.P., Amoroso, C.L., Bubner, T.K. \& Beilby, J.J. (2007) "Job satisfaction of staff and the team environment in Australian general practice", Medical Journal of Australia, Vol 186 No 11, pp 570-573.

Harrison, J.P. \& McDowell, G.M. (2008) "The Role of Laboratory Information Systems in Healthcare Quality Improvement", International Journal of Healthcare Quality Assurance, Vol 21 No 7, pp 679-691.

Hider, P., Lay-Yee, R. \& Davis, P. (2007) "Doctors, practices, patients, and their problems during usual hours: a description of rural and non-rural primary care in New Zealand in 2001-2002", New Zealand Medical Journal, Vol 120 No 1253, pp 1-10.

Ho, K., Lauscher, H.N., Best, A., Walsh, G., Jarvis-Selinger, S, Fedeles, M. \& Chockalingam, A. (2004) "Dissecting Technology-enabled Knowledge Translation: Essential Challenges, Unprecedented Opportunities", Clinical and Investigative Medicine, Vol 27 No 2, pp 70-78.

Hsu, J., Huang, J., Kinsman, J., Fireman, B., Miller, R., Selby, J. \& Ortiz, E. (2005) "Use of EHealth Services Between 1999 and 2002: A Growing Digital Divide", Journal of the American Medical Informatics Association, Vol 12 No 2, pp 164-171.

Huggins, R. \& Izushi, H. (2002) "The digital divide and ICT learning in rural communities: examples of good practice service delivery", Local Economy, Vol 17 No 2, pp 111-122.

Husk, G. \& Waxman, D.A. (2004) "Using Data from Hospital Information Systems to Improve Emergency Department Care", Academic Emergency Medicine, Vol 11 No 11, pp 12371244.

Kaynak, E., Tatoglu, E. \& Kula V. (2005) “An analysis of the factors affecting adoption of electronic commerce by SMEs: Evidence from an emerging market”, International Marketing Review, Vol 22 No 6, pp 623-640.

Keddie, Z. \& Jones, R. (2005) "Information Communications Technology in General Practice: A Cross-Sectional Survey in London", Informatics in Primary Care, Vol 13 No 2, pp 113-123.

Klein, R. (2007) "An Empirical Examination of patient-Physician Portal Acceptance", European Journal of Information Systems, Vol 16 No 6, pp 751-760.

Kuruvilla, S., Dzenowagis, J., Pleasant, A. \& Dwivedi, R. (2004) "Digital Bridges Need Concrete Foundations: Lessons from the Health InterNetwork India", British Medical Journal, Vol 328 No 7449, pp 1193-1196.

Leatherman, J.C. (2000) Internet-based commerce: implications for rural communities, Reviews of Economic Development Literature and Practice, No. 5, US Economic Development Administration, Washington DC.

Lee, C.S. (2001) "An analytical Framework for Evaluating E-commerce Business Models and Strategies", Internet Research: Electronic Network Applications and Policy, Vol 11 No 4, pp 349-359.

Lee, S-Y., Gholami, R. \& Tong, T.Y. (2005) “Time series analysis in the assessment of ICT impact at the aggregate level - lessons and implications for the new economy", Information \& Management, Vol 42 No 7, pp 1009-1022. 
Lepnurm, R., Dobson, R., Backman, A. \& Keegan, D. (2007) "Factors Associated with Career Satisfaction Among General Practitioners in Canada", Canadian Journal of Rural Medicine, Vol 12 No 4, pp 217-230.

Leung, G.M., Yu, P.L.H., Wong, I.O.L., Johnston, J.M. \& Tin, K.Y.K. (2003) "Incentives and Barriers that Influence Clinical Computerisation in Hong Kong: A Population Based Physician Survey", Journal of the American Medical Informatics Association, Vol 10 No 2, pp 201-212.

Lievens, F. \& Jordanova, M. (2004) "Is There a Contradiction Between Telemedicine and Business?", Journal of Telemedicine and Telecare, Vol 10 No 1, pp 71-74.

Lorence, D.P. (2008) "Outsourcing Services in partial Digital Environments: Assessing management Preferences Where Paper is King", Journal of Computer Information Systems, Vol 48 No 3, pp 103-110.

Lougheed, T. (2004) "Wireless Points the Way in Africa", Appropriate Technology, Vol 31 No 3.

Lucas, H. (2008) "Information and Communications Technology for Future Health Systems in Developing Countries", Social Science and Medicine, Vol 66 No 10, pp 2122-2132.

MacGregor, R.C. (2008) The Adoption of E-commerce in SMEs: The Role of Strategic Alliances, Verlag, Germany.

MacGregor, R.C. \& Vrazalic, L. (2007) E-commerce in Regional Small to Medium Enterprises, IGI Global, Hershey, USA.

Marang-van de Mheen, P., Hollander, E-J.F. \& Kievit J. (2007) "Effects of study methodology on adverse outcome occurrence and mortality”, International Journal for Quality in Health Care, Vol 19 No 6, pp 399-406.

Martin, S., Kelly, G., Kernohan, W.G., McCreight, B. \& Nugent, C. (2009) "Smart Home technologies for Health and Social Care Support", The Cochrane Collaboration, Vol 2, pp 111.

Mechanic, D. (2008) "Rethinking medical Professionalism: The Role of Information Technology and Practice Innovation", The Millbank Quarterly, Vol 86 No 2.

Mehrtens, J., Cragg, P.B. \& Mills, A.M. (2001) “A Model of Internet Adoption by SMEs”, Information \& Management, Vol 39 No 3, pp 165-176.

Mohr, M. (2008) "Telemedicine in oncology: European perspective", Health Technology \& Informatics, Vol 131, pp 255-261.

O’Donnell, A., Gilmore, A., Cummins, D. \& Carson, D. (2001) “The Network Construct in Entrepreneurship Research: A Review and Critique”, Management Decision, Vol 39 No 9, pp 749-760.

Olatunde, S., Leduc, E.R. \& Berkowitz, J. (2007) "Different practice patterns of rural and urban general practitioners are predicted by the General Practice Rurality Index", Canadian Journal of Rural Medicine, Vol 12 No 2, pp 73-80.

Overall, C.M. \& Blobel, C.P. (2007) "In Search of partners: linking extracellular proteases to substrates”, Nature Reviews Molecular Cell Biology, Vol 8 No 3, pp 245-257.

Papazafeiropoulou, A. \& Gandecha, R. (2007) "Interpretive Flexibility Along the Innovation Decsion Process of the UK NHS Care Records Service ((NCRS): Insights from a Local 
Implementation Case Study", International Journal of Technology and Human Interaction, Vol 3 No 2, pp 1-12.

Parker, C.M. \& Castleman, T. (2007) "New directions for research on SME-eBusiness: insights from an analysis of journal articles from 2003 to 2006", Journal of Information Systems and Small Business, Vol 1 No 1-2, pp 21-40.

Parker, C.M. \& Castleman, T. (2009) "Small firm eBusiness adoption: a critical analysis of theory", Journal of Enterprise Information Management, Vol 22 No 1/2, pp 167-182.

Pascoe, T., Foley, E. \& Hutchinson, R. (2005) "The changing face of nurses in Australian general practice", Australian Journal of Advanced Nursing, Vol 23 No 1, pp 44-50.

Pelletier-Fleury, N., Lanoe, J.L., Philippe, C., Gagnadoux, F., Rakotonanahary, D. \& Fleury, B. (1999) "Economic Studies and Technical Evaluation of Telemedicine: The Case of Telemonitored Polysomnography", Health Policy, Vol 49, pp 179-194.

Qavi, T., Corley, L. \& Kay, S. (2001) "Nursing Staff Requirements for Telemedicine in the Neonatal Intensive Care Unit", Journal of End User Computing, Vol 13 No 3, pp 5-13.

Rahimi, B. \& Vimarlund, V. (2007) "Methods to evaluate health information systems in healthcare settings: a literature review", Journal of Medical Systems, Vol 31 No 5, pp 397-432.

Raisch, W.D. (2001) The E-marketplace: Strategies for Success in B2B, McGraw-Hill, New York.

Raymond, L. (2001) “Determinants of Web Site Implementation in Small Business”, Internet Research: Electronic Network Applications and Policy, Vol 11 No 5, pp 411-422.

Reardon, J.L. \& Davidson, E. (2007) "An Organisational Learning perspective on the Assimilation of Electronic Medical Records Among Small Physician Practices", European Journal of Information Systems, Vol 16 No 6, pp 681-694.

Riehle, M.A., Bergeron, D. \& Hyrkas, K. (2008) "Improving Process while Changing Practice: FMEA and medical administration", Nursing Management, Vol 39 No 2, pp 33-34.

Robinson, J.C., Casalino, L.P., Gillies, R.R. \& Rittenhouse, D.R. (2009) "Financial Incentives, Quality Improvement Programs, and the Adoption of Clinical Information Technology", Medical Care, Vol 47 No 4, pp 411-417.

Sargeant, J. (2005) "Medical education for rural areas: Opportunities and challenges for information and communications technologies", Journal of Postgraduate Medicine, Vol 51 No 4, pp 301306.

Shohet, I.M. \& Lavy, S. (2004) "Healthcare Facilities Management: State of the Art Review", Facilities, Vol 22 No 7/8, pp 210-220.

Simon, S.R., Kaushal, R., Cleary, P.D., Jenter, C.A., Volk, L.A., Poon, E.G., Orav, E.J., Loc, H.G., Williams, D.H. \& Bates, D.W. (2007) "Correlates of Electronic Health RecordAdoption in Office Practices: A Statewide Survey", Journal of the American Medical Informatics Association, Vol 14 No 1, pp 110-117.

Simunovic, R., Katic, M., Todorovic, G., Vinter-Repalust, N. \& Petric, D. (2007) "Differences between rural and urban general practice activities", Acta Medica Croatica, Vol 61 No 1, pp 13-18.

Skane, D. (1985) Elementary Statistics, Addison-Wesley, Reading. 
Smallbone, D., North, D., Baldock, R. \& Ekanem, I. (2002) Encouraging and supporting enterprises in rural areas, Report to the Small Business Service, London.

Stahl, B.C. \& Brooke, C. (2008) "The Contribution of Critical IS Research", Communications of the ACM, Vol 51 No 3, pp 51-55.

Stevanovic, R., Stanic, A. \& Varga, S. (2005) "Information Systems in Primary Health Care", Acta Medica Croatica, Vol 59 No 3, pp 209-212.

Swan, G.M., Selvaraj, S. \& Godden, D.J (2008) "Clinical peripherality: development of peripherality health services", BMC Health Services Research, Vol 8 No 23.

Tjora, A.H \& Scrambler, G. (2009) "Square Pegs in Round Holes: Information Systems Hospital and the Significance of Contextual Awareness", Social Science and Medicine, Vol 68 No 3, pp 519-525.

Tolhurst, H. \& Stewart, M. (2005) "Becoming a GP", Australian Family Physician, Vol 34 No 3, pp 204-206.

Tolhurst, H., Madjar, I., Schultz, L. \& Schmidt, A. (2004) "Nurses in urban and rural general practice", Australian Family Physician, Vol 33 No 3, pp 185-190.

Valcke, M. \& De Wever, B. (2006) "Information and Communication Technologies in Higher Education: Evidence-based Practices in Medical Education", Medical Teacher, Vol 28 No 1, pp 40-48.

Veitch, C. \& Crossland, L.J. (2005) "Medical family support needs and experiences in rural Queensland", Rural and Remote Health, Vol 5 No 4, pp 1-11.

Vrazalic, L., MacGregor, R.C., Bunker, D.J., Carlsson, S. \& Magnusson, M. (2002) "Electronic Commerce and Market Focus: Some Findings from a Study of Swedish Small to Medium Enterprises”, Australian Journal of Information Systems, Vol 10 No1, pp 110-119.

Wan, Q., Harris, M.F., Powell-Davies, G., Jayasinghe, U.W., Flack, J., Georgiou, A., Burns, J.R. \& Penn, D.L. (2007) "Cardiovascular risk levels in general practice patients with type 2 diabetes in rural and urban areas", Australian Journal of Rural Health, Vol 15 No 5, pp 327333.

Waring, T. \& Wainwright, D. (2002) "Enhancing Clinical and management Discourse in ICT Implementation", Journal of Management in Medicine, Vol 16 No 2/3, pp 133-149.

Whitten, P., Mylod, D., Gavran, G. \& Sypher, H. (2008) "'Most Wired Hospitals' Rate Patient Satisfaction", Communications of the ACM, Vol 51 No 4, pp 96-102.

Wilkinson, D., Laven, G., Pratt, N. \& Beilby, J. (2003) "Impact of undergraduate and postgraduate rural training, and medical school entry criteria on rural practice among Australian general practitioners: national study of 2414 doctors", Medical Education, Vol 37, pp 809-814.

Woloschuk, W. \& Tarrant, M. (2004) "Do Students from Rural backgrounds Engage in Rural family practice More than their Urban-Raised Peers", Medical Education, Vol 38, pp 259-261. 
